\title{
MODERN TECHNOLOGIES IN TEACHING LITERATURE
}

\author{
Milena Škobo \\ Faculty of Philology, \\ Sinergija University, \\ Bijeljina, Republic of Srpska
}

\begin{abstract}
:
The aim of this paper is to identify and analyze the latest technologies in second language teaching, notably teaching English literature to 'digital natives', the modern generations of students raised in media-saturated world who need the instructors and educators in good command of the most recent teaching methods in order to excel academically. The paper sheds a new light on the second language acquisition in the context of reading and interpreting both contemporary and classic literary texts by using digital tools, social media and other sites of Internet. By offering a thorough analysis of the impact of modern technologies on teaching literature, we endeavor to determine the position of literature in the 21st century and point to its significance for students' mental, emotional and moral development.
\end{abstract}

Keywords:

literature, digital era, digital tools, social media, Facebook.

\section{INTRODUCTION}

In the era in which being digitally literate is no longer a luxury or a matter of choice but a necessity, it is important for teachers to consciuously realize the benefits of information and communication technologies in order to use them adequately in the process of transmission of both theoretical and practical knowledge to students. Teachers should, therefore, be able to create the environment that successfully promotes a practical usage of new technologies in education, particularly in language teaching, as this field has always been regarded as the one in line with the ongoing innovation processes in the world of IT. If properly encouraged to use Internet, digital tools, social media and similar sources, the students will be able to gain and evaluate additional knowledge needed for interdisciplinary research lying in the core of successful business ethics, intensify their mental functions and develop a team-building spirit. Deployment of Bloom's Taxonomy Map and online educational tools 
such as Popplet, Facebook, Voicethread, Google Search and Trello in the course of Applied Linguistics and Language Teaching 2 at the Faculty of Philology at Sinergija University in Bijeljina proved to be particularly efficient and effective since the students successfully demonstarted the use of all higher-order thinking skills [1].

The $21^{\text {st }}$ century has equipped students with a variety of online resources such as community-based and collaborative-knowledge-exchange systems [2] and an easy access to various digital paltforms. Rather than passively consuming information, the students create personal information networks and connect with various learning communities. As digital natives prone to multitasking and fast information processing, the students are in constant demand of more sophisticated teaching methodologies that challenge traditional education systems. Language teaching is perhaps the most open and adaptable to the integration of the latest technologies since it is interdisciplinary in its nature and as such more ready to embrace the novelties originating from distinctive scientific fields. Teaching literature under the umbrella of language teaching is even more challenging if considered in the light of its adjustment to the latest developments in the IT world, since it may be quite challenging to bridge the gap between love of technology and love of a written/ spoken word as a part of the artistic expression.

Compared to other subjects and courses, teaching literature has proved to be most resistant to the integration and use of modern technologies, as literature was predominantly associated with deeply spiritual, emotional and mental notions that could hardly be linked with the utilitarian world of technology. If we make use of technology in teaching literature despite the fact that we know that technology is intimately bound with the dehumanization of society, how can we successfully and adequately "identify, explore and interpret the human values lying in the core of any literary work"? [3]. Taking this into consideration, there is a strong need for a redefinition of the goals set and methodologies used in teaching literature, in order to harmonize the traditional and conventional approaches with the innovative and more modern ones. Many scholars address the question of how new media influence the way we read and understand the literature written prior to the digital age. They mostly agree that literature teachers need to include new media such as periodicals, films, images, digital texts, blogs, Web sites, online videos, etc. into the literature classroom and point to the importance of acknowledging the fact that these texts are being woven into both our culture and literate experience [3] [4]; [5]; [6]; [7].
Conversely, the question that arises from the need for IT integration in teaching practices is the following: how can the teachers balance academic loads and maintain high standards of instructions while keeping pace with new technologies?

\section{INNOVATIVE WAYS OF READING AND INTERPRETING LITERARY TEXTS}

The use of new forms of media - video games, graphic novels, interactive hypertexts, language platforms or digital tools - in teaching literature inspires students to think critically as the skills they develop by analyzing these media forms can be applied to studying traditional literary texts. Also, teaching a traditional literary text can go along with its reinterpretation in newer media, as [8] notices in his blog about the use of technology in teaching literature by taking as an example 'chooseyour-own-adventure-style' game /http://gamebookadventures.com/gamebooks/to-be-or-not-to-be/ based on Shakespeare's Hamlet. Namely, in this game entitled 'To Be or Not to Be' the players are allowed to decide what happens next in the narrative by choosing between three Shakespeare's characters. They can 'play as Hamlet and revenge their father's death', 'play as Ophelia and make scientific discoveries', and 'play as King Hamlet, Sr. and die on the first page'. The game features tiny Yorick skulls that mark the choices Shakespeare took in his play. The players may opt for following these skulls for the original story or create their own adventure. The game combines time travel, pirate fighting and murder investigation with specially composed soundtrack and sound effects. The players can listen to the narration as they play the game, learn new words and phrases and look for secret messages hidden throughout the gamebook. Also, the game uses dyslexic friendly font support to aid readers with dyslexia. The use of such media form adds new meanings to the already existing interpretations of Shakespearean play and triggers new discussions arising from the textual analysis.

If used adequately, Internet can be an immensely significant source of creativity, notably when it comes to opening discussions and debates regarding moral dilemmas that are in the core of the greatest literary works. By setting up a forum or 'comment section' for discussing the novels analyzed during the literature classes, the students may feel free to ask and answer questions regarding the book they are reading and the teacher can anytime challenge the students by assigning various problem-solving tasks regarding the book in question. 
Posting comments and replying to them anytime can save time and make teacher's efforts to help students get the gist of the book less intense. In addition to this, the teacher should restrict access to the forum or comment section to students and remind them of privacy concerns. Also, for the sake of the privacy protection, the students should be encouraged to use nicknames rather than their real names and provide as little information about themselves as possible.

Technology in literature is also used to enhance traditional reading experience. One of the language platforms used for such purposes is the 'Actively Learn' platform /https://www.activelylearn.com/, which makes use of e-books that are now widely used in literature classes. The platform extends the learning process that takes part in the classroom beyond the walls of the institution and offers the teacher's constant support to students. Namely, by using this platform the teacher is allowed to embed comments, questions and annotations into an ebook's text anytime he or she finds suitable. The teacher sends his or her own notes through the internet directly to the students' copies of the e-books. Simultaneously, the students are allowed to write their own notes, ask questions or comment on the notes that other students have written, thus creating a strong bond regarding the student-student or student-teacher relationship.

The use of digital tools can be quite beneficial and inspiring in reading and interpreting both traditional and modern literary texts. The use of technology at literature classes is explored in the text written by Mark Lieberman who lists some of the most innovative ways of using digital tools that has already been put into practice by various teachers at Universities across America [9]. For the purpose of this paper we singled out the use of story maps by Allison Fagan, associate professor of English at James Madison University in Virginia, who encouraged students to use 'Esri Story Map' tool during the course on literature regarding undocumented immigration. Due to the limited length of this paper, we will briefly explain how this web tool works in context, without providing a detailed procedure.

Esri Story Map /https://www.esri.com/en-us/about/ about-esri/overview/ is a digital tool that enables students to combine maps, places, locations, geography and narrative text for creating engaging stories that may contain a variety of multimedia materials such as videos, images, shapes, etc. This digital tool is particularly useful for making a link between a work of fiction and a current real life situation. For instance, the migration process that occurs both in real time, i.e. the problems with illegal entries at the U.S.-Mexico border explored by Fagan and her students, and in a work of fiction, may be successfully explored by using this digital tool. During the semester-long project conducted by Fagan, the students used this tool to get a deeper understanding of the impact of a character's location on their experience. The students needed to conduct a thorough research into historical events and place them on the same map. Though struggling at first, towards the end of the course, as Fagin notices, the students began to feel more comfortable with the use of the web tool and opted for more sophisticated tasks than the program would allow.

Exploring such undergoing processes that affect the modern society (i.e. migration, global warming, climate change) and linking them with those the characters face within a work of fiction (i.e. the story of Rjepnin, a Milos Crnjanski's tragic hero, a Russian immigrant who settled in London / A Novel about London, 1971/, warns about difficulties the immigrants face in their process to fit into the world different from theirs, or Margaret Atwood's story of a mad scientist /Oryx and Crake, 2003/ that warns about the disturbing effects of technology on the science-driven society) by using the story maps might be immensely beneficial in literature teaching. Even the simplest story maps activate deeper levels of thinking and raise students' awareness of the current social, cultural and political issues.

Apart from iPads that enable the circulation of information and promote the exchange of ideas in literary classes, the use of e-clicker questionnaires challenges traditional approaches to reading and reviewing a literary work. As they shorten the time needed for reviewing the content of a literary work, the e-clicker questionnaires have proven to be an effective and very popular tool among the students [10]. Instead of raising their hands when the teacher asks a question, the students press the buttons on the e-clicker and their answers are analyzed by the computer. With the use of e-clickers in the classroom the literature classes become more interesting. This device ensures the relative anonymity of the students' answers. If one e-clicker is given to a group of students, discussion may be easily triggered among them. However, since e-clickers require a simple form of answers (Yes/No or multiple choice), it is advisible to use them occasionally or in combination with other tools that stimulate critical thinking in literature classes. 


\section{SOCIAL MEDIA IN LITERATURE TEACHING}

Since social media sites are widely used for promotion and networking by contemporary literary authors, there are various ways in which teachers may engage students in the process of gathering information about the authors and their literary works so that they could better understand their fiction. Following the contemporary author's posts and activity on social networks may give students an insight into the themes that generally interest the author in question since they usually serve as a bounteous source of inspiration for his or her fiction. For example, Margaret Atwood's concern for the environment and global warming, the recurrent themes in her writings (i.e. exploring eco-fiction in her MaddAddam trilogy), is apparent if you check her Facebook page /https://www.facebook.com/pg/MargaretAtwoodAuthor/about/?ref=page_internal/, since she posts frequently about the fatal consequences of pollution and inadequate use of plastic bags. Her concern for the environment is seen in constant promotion of 'Ecosia', a search engine that donates $80 \%$ or more of its profits to nonprofit organizations that focus on reforestation, on her Facebook page. In light of this, we chose to present the assignment set by Wiseman and Wagler, the teachers at University of Nebraska, since it provides a good example of how similar use of social media works in practice. The main goal of their assignment is helping students to develop critical thinking skills about media consumption as they participate in literary communities and explore new venues for writing [11].

Task 1 For the purpose of this assignment students use smartphones with access to social media sites in order to analyze and gain access to posts written by contemporary writers. For a six-week time, students are asked to participate on a social media site of their choice (Facebook, Twitter, etc.) as they follow an author of their choice who frequently posts content. Namely, the students are encouraged to think about their reading and writing interests and the authors they love (e.g. a Margaret Atwood fan might follow her on Facebook or Twitter/https://twitter.com/MargaretAtwood/, visit 'Atwood Society' /https://twitter.com/atwoodsociety/, or visit her website (http://margaretatwood.ca), while a Harry Potter fan might enjoy exploring 'Pottermore' / https://www.wizardingworld.com/). Then, the students are advised to focus on the author's posts and his or her interactivity with followers. It is also expected from the students to post and interact with others at the site.
Students are asked to document their findings and reflections and evaluate the author's site (its purpose, audience, genre and style, and cultural context). The evaluation involves one- to two-page analysis of a given aspect of a social site or on author's use of that site. Alternatively, the teachers may offer an analysis as a guided, in-class writing activity, where students write down what they are noticing on their sites. Also, small and large group discussions may be organized together with workshops to help students relate their peers' findings to their own. After a final workshop, students are to give five-to-seven-minute presentation of their portfolio. The portfolio including screenshots or other artifacts that support students' findings is later translated into PowerPoint presentation.

Apart from learning more about the authors they admire and discovering new ones, this assignment offers students an excellent opportunity to explore the innovative ways in which authors, readers and presses use new technologies to communicate, discuss and explore literature. This assignment gives students an insight into digital reading and writing communities and encourages critical thinking as the students consume and produce content in an online environment [11]. Finally, the workshops that are part of the assignment encourage idea exchange and help students develop skills in revision, argument and peer feedback.

Facebook with its Timeline feature can also be a useful tool for an in-depth analysis of a chosen literary text, since it allows students to visualize events from the plot, the author's life, or socio-historical context of the literary work. The assignment set before the second-year students attending the course of Victorian literature at the Faculty of Philology at Sinergija University during the school year 2017/2018 consisted in creating a page of the chosen literary character (or its corresponding film character) while logged in on their Facebook accounts (Page name and category were requested) and filling in all the necessary information concerning the character's life. Since the Timeline feature allows an exact tracking of the plot developments, as well as the significant turning points in his/her life and the interactions among characters within the fictional world set in the specific socio-historical context, recreating the identities of the students' characters was neither time-consuming nor a complex task.

Task 2 This assignment was used instead of oral presentations the students were asked to give in order to earn extra points. The students worked in groups of 4 to 5 during a two-week long period. Each student was asked to choose one literary character from the book 
we were reading at that time [12], create the character's profile as a page, complete the information section and 'become Friends' with other fictional characters in order to interact on Facebook. At this point, the students chose the main characters of Oscar Wilde's novel: Dorian Gray, a painter Basil Hallward, a notorious instigator Lord Henry Wotton and Sybil Vane, an actress in love with Dorian. In order to make their characters more convincing, the students were also asked to watch one of the two film versions based on Wilde's novel: a 1945 American horror-drama film directed by Albert Lewin and a 2009 British fantasy-horror drama directed by Oliver Parker.

Filling in the information section of a character's profile was quite purposeful, since it assumed the students' engagement with finding the concrete facts and information about the character's life, such as Basic Info, Work and Education, History by Year, Relationship Status, etc. At the same time, the students classified the information they discovered and decided what should be revealed and hidden to the public. The deeds and events that the characters (i.e. Dorian Gray) were unwilling to reveal since they damaged their reputation (the deteriorating portrait of Dorian Gray showing his true nature) might be exposed by other characters (i.e. Basil, who finds out the truth about Dorian's changing portrait) by tagging the character in an incriminating photo or posting on his wall (in this concrete case, the narrative would take an unexpected turn that would lead to surprising versions of the novel's ending).

The students as creators of the character's page are given the opportunity to decide what their character should 'Like' or add to his or her list of 'Favorites', including books, people they admire, music, events, etc. This Facebook feature proved to be quite useful as it encouraged the students to go deeper into the analysis of the original text and search for information supporting their decisions what to like on the social network (i.e. Dorian Gray liked the pages about fashion, style and art and all newfangled magazines; he was also 'interested' in the events such as 'dinner parties', 'cocktail parties', 'theatre going', or the events that suggested 'a life of debauchery'). By considering what Dorian Gray would like, who he would interact with, what events he would choose to visit, the students are subconsciously dragged into the process of constructing the character's identity in the context of social media behaviors. Also, since some of the options that Facebook offers are unavailable to character pages, the students had to find the way how to express their disliking or antipathy towards certain characters (i.e. Lord Henry's disliking of Sybil Vane was expressed by Lord Henry's observations concerning her poor acting).

In addition to this, the students made use of 'status update' option on Facebook, where they were able to engage in conversations with multiple characters chosen from the book, share their view of key events or specific scenes from the text and trigger discussions in real time. As the narrative unfolds, the students update their status and engage themselves in the process of character development. They search for interesting conversations in the original text and share their character's views on many issues. For instance, Lord Henry's derogatory view of women is expressed by posting the following conversation between Lord Henry and Dorian: "My dear boy, no woman is a genius. Women are a decorative sex. They never have anything to say, but they say it charmingly. Women represent the triumph of matter over mind, just as men represent the triumph of mind over morals" [12]. Simultaneously, by uploading a photo or video, another feature offered by Facebook, the students demonstrated their creativity in a variety of ways. While some students opted for creating the characters following the information given in the text itself, others chose to do the 'remake', that is, to transform their nineteenth-century characters into their twenty-first century counterparts by creating and uploading photos or videos showing how they thought their characters would dress, talk and behave if they existed in digital era.

In one of the versions created by the students Dorian Gray's photo that revealed his moral deviance was exposed on his Facebook Timeline by revengeful James Vane, a brother of deceased Sybil Vane, while he was attending the party organized in his honor for winning the first prize in 'Beauty Award Online Competition'. As people at the party, Dorian's connoisseurs, followers and 'false' friends, were constantly online, they could immediately see the post on his wall, which resulted in damaging Dorian's reputation to such an extent that repair was not possible. Despite the fact that our Dorian immediately deleted a compromising photo, his dark secret had been revealed. As a consequence, this triggered fast reactions of the people (and characters) who were eager to leave comments or emoticons expressing their shock, surprise or disgust beneath the photo. At that very moment, the profile picture of 'forever' young and beautiful Dorian that he chose for himself was changed into the portrait of an old, gruesome and despicable man whose soul was as rotten as the face on his changed profile picture. 
By translating the literary work into the language of social media familiar to them, the students are invited and encouraged to discuss unfamiliar and often complex literary perspectives and add new meanings to the literary works interpreted from multiple perspectives.

\section{CONCLUSION}

Nowadays it is expected from the teachers to provide the environment that will enable students who have grown up using a multitude of digital platforms to access information easily, communicate across platforms dispersed in a wide range of media and understand information shared online. To what extent will the teacher be able to activate the learning process within the framework of new technologies depends on the competences of the teacher and his or her readiness to implement new technologies in teaching, the complexity of learning itself and the complexity of the available teaching tools. In view of this, some scholars started to use the term 'transliteracy' defining it as "the ability to read, write and interact across a range of platforms, tools and media from signing and orality through handwriting, print, TV, radio and film, to digital social networks" [13]. The integration of interactive media as a teaching tool into the literature classes proves to be a stimulating and engaging way of addressing various communication concepts and challenges of the $21^{\text {st }}$ century.

Innovative ways of reading and interpreting literary texts identified and explored in this paper trigger the students' motivation, initiate discussion, and raise the students' awareness of the current social/political/ global issues. By setting up forums and 'comment section' for online discussion of moral dilemmas within literary texts the students are more willing to actively participate in problem solving tasks set by the teachers. The use of 'Actively Learn' platform that enables students and teachers to embed comments, questions and annotations into an e-book's text anytime, enhances the learning process since the students are able to clarify whatever they find confusing within the literary text, while Esri's Story Map establishes the relation between a written word and a real life experience.

The tasks set before students as a way of implementing social media in literature teaching presented in this paper proved to be quite effective. In Task 1 it is showed that the use of Facebook, Twitter or other social media network for the purpose of assessing and evaluating the contemporary authors' posts and checking their interactivity with followers gives students an insight into digital reading and writing communities and encourages critical thinking. The students' findings presented during the final workshop in the form of a portfolio and PowerPoint presentation helped students develop skills in revision, argument and peer feedback. The Task 2 dealing with the use of Facebook with its Timeline feature for the purpose of creating a page of the chosen literary character turned out to be quite beneficial to the second-year students attending the course on Victorian Literature at the Faculty of Philology at Sinergija University. Translating the traditional text into new media offered multiple perspectives and added new meanings to the literary text. The students tackled the complex issues that appeared in the text without much trouble. By transforming the nineteenth-century novel into the twenty-first century story the students were able to detect the timeless themes and questions that obsess the people regardless of their age or the time they live in.

Therefore, it can be concluded that, by adequate implementation of social media in teaching literature that includes the students' consuming and producing content in an online environment, teachers may help students think critically about their surroundings and make thoughtful, critical and analytical inquiries about social media in general.

\section{REFERENCES}

[1] M. Nikolić and T. Dabić, "The Bloom's Taxonomy Revisited in the Context of Online Tools," in International Scientific Conference on ICT and E-Business Related Research, Singidunum University, Belgrade, Serbia, 2016.

[2] S. T. d. Zepetnek and A. L. Azcárate, "Mapping the World, Culture, and Border-crossing.," in Education, Interculturalism, and Mapping a New Europe, Kaohsiung, National Sun Yat-sen UP, 2010, pp. 38-49.

[3] M. Škobo and B. Đerić-Dragičević, "Teaching English Literature in the Digital Era," in Sinergija 2019 - XX International Scientific Conference, Sinergija University, Bijeljina, Republic of Srpska, 2019.

[4] R. Scholes, "The English Curriculum After the Fall," Pedagogy Critical Approaches to Teaching Literature Language Composition and Culture, pp. 229-240, 2010.

[5] E. Cushman, "New Media Scholarship and Teaching: Challenging the Hierarchy of Signs," Pedagogy Critical Approaches to Teaching Literature Language Composition and Culture, pp. 63-79, 2011.

[6] J. Parks, "A Digital Approach to Teaching Postmodern Literature," in Teaching Literature with Digital Technology, Boston, MA: Bedford/St. Martin's, 2016, pp. 110-121. 
[7] M. Nikolić, "The use of audio and video recordings in English language teaching," in Sinergija 2017 XVIII International Scientific Conference, Sinergija University, Bijeljina, 2017.

[8] D. Spencer, "Prestwick House," July 2015. [Online]. Available: https://www.prestwickhouse.com/blog/ post/2015/07/using-technology-to-teach-literature.

[9] M. Lieberman, "How Technology Enhances Literature Learning," 31 January 2018. [Online]. Available: https://www.insidehighered.com/digital-learning/ article/2018/01/31/technology-tools-work-literatureclassrooms.

[10] G. Boruszko, "New Technologies and T echnologies and Teaching Compar eaching Comparative Liter e Literature," CLCWeb: Compar eb: Comparative Liter e Literature and Cultur e and Culture, 2013.
[11] L. M. Wiseman and A. Wagler, "Shaking the Magic 8 Ball: Social Media for Readers and Writers," in Teaching Literature with Digital Technology, Boston, MA: Bedford/St. Martin's, 2016, pp. 3-20.

[12] O. Wilde, The Picture of Dorian Gray, Ware, Hertfordshire: Wordsworth Editions Limited, 2001.

[13] S. Thomas, C. Joseph, J. Laccetti, B. Mason, S. Mills, S. Peril and K. Pullinger, "Transliteracy: Crossing Divides," First Monday: Peer-Reviewed Journal on the Internet 12, pp. 2-3, 2007. 